\title{
Anabases
}

ANABASES Traditions et réceptions de l'Antiquité

18 | 2013

Varia

\section{Otto Neugebauer's Vision for Rewriting the History of Ancient Mathematics}

David E. Rowe

\section{(2) OpenEdition \\ 12 Journals}

\section{Electronic version}

URL: http://journals.openedition.org/anabases/4450

DOI: 10.4000/anabases.4450

ISSN: 2256-9421

\section{Publisher}

E.R.A.S.M.E.

\section{Printed version}

Date of publication: 1 October 2013

Number of pages: 175-196

ISSN: 1774-4296

\section{Electronic reference}

David E. Rowe, «Otto Neugebauer's Vision for Rewriting the History of Ancient Mathematics »,

Anabases [Online], 18 | 2013, Online since 01 November 2016, connection on 21 October 2019. URL :

http://journals.openedition.org/anabases/4450 ; DOI : 10.4000/anabases.4450 


\section{Otto Neugebauer's Vision for Rewriting the History of Ancient Mathematics}

DAVID E. Rowe

The common belief that we gain "historical perspective" with increasing distance seems to me utterly to misrepresent

the actual situation. What we gain is merely confidence in generalizations which we would never dare make if we had access to the real wealth of contemporary evidence.

Otto Neugebauer, The Exact Sciences in Antiquity (Neugebauer, 1969, viii)

Otto Neugebauer (1899-1990) was, for many, an enigmatic personality. Trained as a mathematician in Graz, Munich, and Göttingen, he had not yet completed his doctoral research when in 1924 Harald Bohr, brother of the famous physicist, invited him to Copenhagen to work together on Bohr's new theory of almost periodic functions. Quite by chance, Bohr asked Neugebauer to write a review of T. Eric Peet's recently published edition of the Rhind Papyrus (Neugebauer, 1925). In the course of doing so, Neugebauer became utterly intrigued by Egyptian methods for calculating fractions as sums of unit fractions (e.g. $3 / 5=1 / 3+1 / 5+1 / 15$ ). When he returned to Göttingen, he wrote his dissertation on this very topic. In 1927 he published the first of many researches on Babylonian mathematics and astronomy, a pioneering study on the evolution of the sexagesimal (base 60) number system (Neugebauer, 1927). These works received high praise from leading Egyptologists and Assyriologists, helping to 
launch Neugebauer's career as a historian of ancient mathematics and exact sciences. Indeed, he would go on to revolutionize research in these areas, leaving a deep imprint on our understanding of these ancient scientific cultures to this very day.

Yet Neugebauer's general orientation as a historian seems strangely remote from today's perspective, so much so that even scholars who know his work well and respect it highly have great difficulty identifying with his methodological views. One who worked closely with him during his later career at Brown University, Noel Swerdlow, gave a most apt description of the "zwei Seelen" that dwelled within Otto Neugebauer and that colored all his work:

At once a mathematician and cultural historian, Neugebauer was from the beginning aware of both interpretations and of the contradiction between them. Indeed, a notable tension between the analysis of culturally specific documents, whether the contents of a single clay tablet or scrap of papyrus or an entire Greek treatise, and the continuity and evolution of mathematical methods regardless of ages and cultures, is characteristic of all his work. And it was precisely out of this tension that was born the detailed and technical cross-cultural approach, in no way adequately described as the study of "transmission", that he applied more or less consistently to the history of the exact sciences from the ancient Near East to the European Renaissance.

But if the truth be told, on a deeper level Neugebauer was always a mathematician first and foremost, who selected the subjects of his study and passed judgment on them, sometimes quite strongly, according to their mathematical interest (Swerdlow, 1993, 141-142).

Taking up this last point, one can easily appreciate why Neugebauer's approach to history persuaded few, while provoking some of his detractors to take a firm stand against his methodological views and what they felt was a deleterious influence on studies of the ancient sciences ${ }^{1}$. Neugebauer firmly believed in the immutable character of mathematical knowledge, which meant that his field of historical inquiry, the exact sciences, differed from all other forms of human endeavor in one fundamental respect: in this realm there was no room for historical contingency. The methodological implications Neugebauer drew from this were simple and clear: once an investigator had cracked the linguistic or hieroglyphic codes that serve to express a culture's scientific knowledge he or she then suddenly held the keys to deciphering ancient sources. And since the content of these sources pertained to mathematical matters, one could, in principle, argue inductively in order to reconstruct what they originally contained, namely a fixed and determinable pattern of scientific results. Clearly, this type of puzzle solving held great fascination for Neugebauer, and he practiced it with considerable success in his research on Mesopotamian astronomy, beginning in the mid-1930s.

1 The sharpest attack against Neugebauer's methodological approach came from Sabetai Unguru in (Unguru, 1975); for this text and reactions to it, see (Christianidis, 2004). 
Neugebauer's work on Greek mathematics during these politically turbulent times was far scantier. Nevertheless, his views on Greek mathematics formed a central component of his overall view of the ancient mathematical sciences. When it came to purely human affairs, Neugebauer professed that he held no Weltanschauung, and he took pains to make this known to those who, like Oskar Becker, mingled ideology with science (see Siegmund-Schultze, 2009, 163). Regarding historiography, on the other hand, Neugebauer adopted a rigorously empirical approach that worked well in some cases, but often led him to make sweeping claims based on little more than hunches. Not surprisingly, his views on historiography had much to do with the special context in which he first experienced higher mathematics (Rowe, 2012).

\section{Neugebauer's Cornell Lectures}

In 1949, when Otto Neugebauer delivered six lectures on ancient sciences at Cornell University, he was the first historian of mathematics to be given the honor of speaking in its distinguished Messenger lecture series. He did not waste this opportunity. Afterward, he went over his notes and gave the text its final, carefully sculpted form that we find today in the six chapters of Neugebauer's The Exact Sciences in Antiquity, published in 1951 with high-quality plates by Brown University Press (see Fig. 1). The text begins by describing a famous work in the history of art:

When in 1416 Jean de France, Duc de Berry, died, the work on his "Book of the Hours" was suspended. The brothers Limbourg, who were entrusted with the illuminations of this book, left the court, never to complete what is now considered one of the most magnificent of late medieval manuscripts which have come down to us. A "Book of Hours" is a prayer book which is based on the religious calendar of saints and festivals throughout the year. Consequently we find in the book of the Duc of Berry twelve folios, representing each one of the months. As an example we may consider the illustration for the month of September. As the work of the season the vintage is shown in the foreground (Plate 1 [reproduced below]). In the background we see the Château de Saumur, depicted with the greatest accuracy of architectural detail. For us, however, it is the semicircular field on top of the picture, where we find numbers and astronomical symbols, which will give us some impression of the scientific background of this calendar. Already a superficial discussion of these representations will demonstrate close relations between the astronomy of the late Middle Ages and antiquity (Neugebauer, 1969, 3).

Neugebauer went on to note four different types of writing for the numbers that appear in the Book of Hours: Hindu-Arabic as well as Roman numerals, number words (September through December for the seventh to the tenth months of the Roman 
calendar), and alphabetic numbers, here calculated modulo $19^{2}$, the system used in connection with the Metonic lunar cycle. Regarding the latter, he noted that for a given year, the associated number between 1 and 18 was called the "golden number" in the late Middle Ages, after a 13th-century scholar wrote that this lunar cycle excels all others "as gold excels all other metals."

He then comments as follows about the state of scientific progress in the Latin West when seen against the backdrop of earlier developments: "In the twelfth century this very primitive method [for calculating the date of a new moon] was considered by scholars in Western Europe as a miracle of accuracy, though incomparably better results had been reached by Babylonian and Greek methods since the fourth century B.C. and though these methods were ably handled by contemporary Islamic and Jewish astronomers" (Neugebauer, 1969, 8). Clearly, Neugebauer wanted his audience to realize that it was one thing to appreciate a magnificent work of art, quite another to think of it as a canvas for clues about the state of mathematical and astronomical knowledge in the culture within which it was produced (Fig. 2).

For the second edition, he updated the material and added two technical appendices, but he still hoped to have "avoided... converting my lectures into a textbook" (Neugebauer, 1969, ix). Evidently, he valued the less formal form of exposition associated with oral exposition, a hallmark of the Göttingen tradition (Rowe, 2004). Still, Neugebauer grew up in Austria, not Prussia, which may help account for his playful sense of humor. A typical example comes in a passage where he comments on how astronomers took delight in harmonizing their science with anthropocentric religious views, whereas modern celestial mechanics teaches us to be humble creatures living in a solar system conditioned by accidental circumstances.

The structure of our planetary system is indeed such that Rheticus [an early champion of the Copernican theory] could say "the planets show again and again all the phenomena which God desired to be seen from the earth." The investigations of Hill and Poincaré have demonstrated that only slightly different initial conditions would have caused the moon to travel around the earth in a curve [with small loops and]... Nobody would have had the idea that the moon could rotate on a circle around the earth and all philosophers would have declared it as a logical necessity that a moon shows six half moons between two full moons. And what could have happened with our concepts of time if we were members of a double-star system (perhaps with some uneven distribution of mass in our little satellite) is something that may be left to the imagination (Neugebauer, 1969, 152-153).

2 In modular arithmetic, one calculates the remainder on division, so that in the present case, for example $23=4$ modulo 19 . 


\section{Neugebauer and Courant in Göttingen}

Significantly, Neugebauer dedicated this now classic book to "Richard Courant, in Friendship and Gratitude." Elaborating on that dedication in the preface, he wrote that it was Courant who enabled him to pursue graduate studies in ancient mathematics, and he went on to remark: "more than that I owe him the experience of being introduced to modern mathematics and physics as a part of intellectual endeavour, never isolated from each other nor from any other field of our civilization" (Neugebauer, 1969 , vii). Neugebauer was a man who chose his words carefully, and so we may be sure that this public acknowledgement of his debt to Courant was far more than just a friendly gesture. He wrote further that Courant's vision saw mathematics and physics as fields of intellectual endeavor "never isolated from each other nor from any other field of our civilization." This brief remark comes very close to capturing the essence of Neugebauer's own understanding of what it meant to study the history of mathematics as an integral part of human cultural life. Regarding Courant's personal outlook, he described this in connection with the Göttingen mathematical tradition they both shared and valued:

... the real core of his work [consisted] in the conscious continuation and ever widening development of the ideas of Riemann, Klein, and Hilbert, and in his insistence on demonstrating the fundamental unity of all mathematical disciplines. One must always remain aware of these basic motives if one wants to do justice to Courant's work and to realize its inner consistency (Neugebauer, 1963, 1).

As a close ally of Courant, Neugebauer shared a positivist vision of mathematics as an integral part of scientific culture. In particular, both men were deeply influenced by the universalism advocated by Göttingen's two aging sages, Felix Klein and David Hilbert, who broke with an older German tradition in which mathematical research was largely isolated from developments in neighboring disciplines, like astronomy and physics. Hilbert's strong epistemic claims for mathematics had also deeply alienated conservative humanists on the Göttingen faculty, many of whom feared a realignment of traditional disciplinary boundaries (Rowe, 1986). Neugebauer's personal relationship with Richard Courant reflects many of the broader mathematical and scientific interests the two men shared.

As director of the Göttingen Mathematics Institute during the Weimar years, Courant was faced with numerous challenges as he struggled to uphold its international scientific reputation. Part of his strategy was conservative in nature. Through his connections with Ferdinand Springer, Courant launched the famed "yellow series", one of several initiatives that enabled Springer to attain a pre-eminent position as a publisher in the fields of mathematics and theoretical physics (Remmert and Schneider, 2010). Courant was an innovator with a deep belief in the vitality of older traditions. His yellow series looked backward as well as forward; in fact, surprisingly few of its 
volumes betray a commitment to what came to be identified as modern, abstract mathematics. Far more evident was the way in which Courant and his co-editors built on the tradition of Klein and Hilbert, and with the yellow series he found a way to make local knowledge accessible well beyond the borders of Germany. Neugebauer would ultimately devote himself to the study of the same nexus of mathematical sciences in antiquity. For the history of the ancient exact sciences, Springer's short-lived Quellen und Studien series, launched in 1929 and edited by Neugebauer, Julius Stenzel, and Otto Toeplitz, created a new standard for studies in this fast-breaking field.

Soon after Neugebauer arrived in Göttingen in 1922, Courant gave him various special duties to perform at the hub of operations, located on the third floor of the Auditorienhaus. There one found the famous Lesezimmer together with an impressive collection of mathematical models, long cared for by Felix Klein's assistants. Now Neugebauer stood guard while Klein received nearly daily reports through those who were busy helping him prepare his collected works. Neugebauer's new interest in Egyptian mathematics also came to Klein's attention, along with a complaint that he had stuffed all the books on mathematics education tightly together on a high shelf, making them nearly inaccessible. By now Klein was an infirm old man who rarely left his home, which overlooked the botanical garden immediately behind the Auditorienhaus, but he still kept up a busy and tightly organized schedule. Neugebauer remembered how Klein called him over to be gently scolded. When he arrived, Klein greeted him by saying: "there came a new Moses into Egypt and he knew not Pharaoh!" (Reid, 1976, 100) [a play on: "Now there arose up a new king over Egypt, which knew not Joseph", Exodus I.8]. The young Neugebauer surely realized that watching over the Lesezimmer was no trifling matter.

\section{Neugebauer's Revisionist Approach to Greek Mathematics}

Neugebauer saw himself as a "scientific historian"; he had no patience for those who simply wanted to chronicle the great names and works of the past. George Sarton, who did little else, saw the history of science as a humanistic endeavor; nevertheless, he had the highest respect for Neugebauer's achievements. Sarton's views emerge clearly from correspondence during September 1933 with Abraham Flexner. At the time, Flexner was contemplating the possibility of founding a school for studies of science and culture at the Institute for Advanced Study. Sarton thought that Neugebauer was just the man for such an enterprise, a point he made by humbly contrasting the nature of their work: "As compared with Neugebauer I am only a dilettante. He works in the front trenches while I amuse myself way back in the rear-praising the ones, blaming the others; saying this ought to be done, etc.- $\&$ doing very little myself. What Neugebauer does is fundamental, what I do, secondary" (Pyenson, 1995, 268). Neugebauer certainly did view Sarton as a dilettante through and through. When I interviewed him in 1982, he 
made a point of telling me this by lumping him together with Moritz Cantor, another encyclopedist of great breadth and little depth.

Although plans to bring Neugebauer to Princeton came to naught, Harald Bohr managed to arrange a three-year appointment for him in Copenhagen beginning in January 1934. Neugebauer managed to get most of his property out of Germany, but had to abandon a house with a partially paid mortgage. In Copenhagen, his research was supported in part by the Rockefeller Foundation. Almost immediately he began preparing a series of lectures on Egyptian and Babylonian mathematics that he would publish in Courant's yellow series as Vorgriechische Mathematik (Neugebauer, 1934). According to Swerdlow this volume was "as much a cultural as a technical history of mathematics" and represents "Neugebauer's most thorough and successful union of the two interpretations" (Swerdlow, 1993, 145). More striking still is the unfinished character of this work, which represents the first and final volume in a projected trilogy that remained incomplete. Neugebauer had planned to tackle Greek mathematics proper in the second volume, whereas the third would have dealt with mathematical astronomy, both in the Greek tradition culminating with Ptolemy as well as the largely unknown work of late Babylonian astronomers. Thus, his original aim, as spelled out in the foreword to the first volume, was to achieve a first overview of the ancient mathematical sciences in their entirety, something that had never before been attempted.

Swerdlow has offered compelling reasons to explain why Neugebauer dropped this project, one being that he simply found the rich textual sources for Mesopotamian mathematical astronomy far more important than anything he could ever have written about Greek mathematics. Nevertheless, we can trace a fairly clear picture of the line of argument Neugebauer originally had in mind by examining the summary remarks at the conclusion of his Vorgriechische Mathematik as well as some of his other publications from the 1930s. Neugebauer's writings from the 1920s contain few hints that his understanding of ancient mathematics was fundamentally opposed to older views. By the early 1930s, however, his analyses of Babylonian texts led him to a new conception, namely that the Greek penchant for geometrization represented a retrograde step in the natural development of the exact sciences. This did not mean, of course, that he held a low opinion of Euclid's Elements, he simply thought that historians and philosophers had distorted its true place in the history of mathematics. Thus, he once imagined how scholars in some future civilization might easily form a deceptive picture of mathematical knowledge circa 1900 if the only important text that happened to survived were Hilbert's Grundlagen der Geometrie.

In the course of this transition, Neugebauer's assertions about the character of ancient mathematics often took on a strident tone. Particularly suggestive is an essay entitled "Zur geometrischen Algebra", published in 1936 in Quellen und Studien (Neugebauer, 1936). Significantly, Neugebauer takes as his motto a famous fragment from the late Pythagorean Archytas of Tarentum, which reads: "It seems that logistic far excels the other arts in regard to wisdom, and in particular in treating more clearly what it wishes than geometry. And where geometry fails, logistic brings about proofs." 
(Neugebauer, 1936, 245) Much has been written about this passage, in particular about what might be meant by the term "logistic", a matter Jakob Klein discussed at great length in his study "Die griechische Logistik und die Entstehung der Algebra" (Klein, 1936), which appeared alongside Neugebauer's article (it was later translated into English by Eva Brann [Klein, 1968]). In fact, both scholars were chasing after the same elusive goal, though there the similarity ends.

J. Klein was a classical philologist who later became a master teacher of the "Great Books" curriculum at St. Johns College in Annapolis Maryland. Not surprisingly, he was intent on squeezing as much out of Plato as he possibly could. Thus he distinguished carefully between practical and theoretical logistic, offering a new interpretation of Diophantus' Arithmetica that placed it within the latter tradition. Neugebauer had no patience for the nuances of meaning classicists liked to pull out of their texts. Indeed, he had an entirely different agenda. His point was that rigorous axiomatic reasoning in the style of Euclid arose rather late, and that Archytas, a contemporary of Plato, was bearing witness to the primacy of algebraic content over the geometrical form in which the Greeks dressed their mathematics. With that, we can take another step forward toward attaining a closer understanding Neugebauer's Weltanschauung.

Decades earlier, the Danish historian of mathematics H. G. Zeuthen already advanced the idea that the Greeks had found it necessary to geometrize their purely algebraic results after the discovery of incommensurable magnitudes (Zeuthen, 1896) ${ }^{3}$. Neugebauer took up this by now standard interpretation, adopted by Heath and nearly everyone else, but he then went much further, arguing that the algebraic content -found not only in Book II of Euclid but throughout the entire corpus of Apollonius' Conica- could be traced back to results and methods of the Babylonians:

The answer to the question what were the origins of the fundamental problem in all of geometrical algebra [meaning the application of areas, as given by Euclid's proposition...s I.44 and VI.27-29] ${ }^{4}$ can today be given completely: they lie, on the one hand, in the demands of the Greeks to secure the general validity of their mathematics in the wake of the emergence of irrational magnitudes, on the other, in the resulting necessity to translate the results of the pre-Greek "algebraic" algebra as well. Once one has formulated the problem in this way, everything else is completely trivial [!] and provides the smooth

3 Ancient sources only hint at the circumstances surrounding this discovery, which probably took place during the latter half of the fifth century. Before this time, it was presumed that magnitudes of the same kind, for example two lengths, could always be measured by a third, hence commensurable. This is equivalent to saying that their ratio will be equal to the ratio of two natural numbers. This theory had to be discarded when it was realized that even simple magnitudes, like the diagonal and side of a square, have an irrational ratio because their lengths are incommensurable lengths. The discovery of such irrational objects in geometry had profound consequences for the practice of Greek geometry in the fourth century (see Fowler, 1999).

See the discussion below. 
connection between Babylonian algebra and the formulations of Euclid (Neugebauer, 1936, 250, my translation, his italics).

The mathematical concepts underlying this argument are by no means difficult. It must be emphasized, however, that what may seem mathematically trivial (i.e. obvious) should hardly be thought of as historically self-evident. Since Zeuthen's time, it had been customary to interpret Greek problem-solving methods as manipulations closely related to techniques like "completing the square", used to solve quadratic equations. These Greek methods, called applications of areas, occupy a prominent place in Euclid's Elements as well as in his Data, a kind of handbook for problem solving. Neugebauer was struck by the parallelism between certain standard Babylonian problems and the Greek methods for solving very similar problems geometrically (Neugebauer, 1969, 40-41, 149-150).

A typical algebra problem found in several cuneiform tablets from the Old Babylonian period requires that one find two numbers whose sum (or difference) and product are both given (Neugebauer called this the "normal form" leading to a single quadratic equation). This pair of problems, depending on whether the sum or difference is given, can also be found as Propositions 84 and 85 in Euclid's Data. Moreover, according to the neo-Platonic commentator Proclus -on the authority of Aristotle's student, Eudemus, author of a lost History of Geometry written just before Euclid's time- the three types of applications of areas (later used by Apollonius to distinguish the three types of conic sections: ellipse, parabola, and hyperbola) were discovered long before Euclid: "These things, say Eudemus, are ancient and are discoveries of the Muse of the Pythagoreans" (Heath, 1956, 343).

Neugebauer would have been the last to argue that the Pythagoreans had anything to do with this ancient knowledge; for him, the key fact was merely that the original ideas were old, hence likely to have roots in still older cultures from which the Greeks borrowed freely. Having established that the mathematical content of the Babylonian texts was fundamentally algebraic, he now claimed that Mesopotamia was the original source of the algebra underlying the "geometric algebra" uncovered by Zeuthen at the end of the nineteenth century. Neugebauer was fully aware, of course, that his interpretation required a really bold leap of the historical imagination, since making a claim for the transmission of such knowledge over such a vast span of time meant accepting that this mathematical linkage sufficed to fill a gap devoid of any substantive documentary evidence. Summarizing his position, he offered these remarks: "Every attempt to connect Greek thought with the pre-Greek meets with intense resistance. The possibility of having to modify the usual picture of the Greeks is always undesirable, despite all shifts of view... [and yet] the Greeks stand in the middle and no longer at the beginning" (Neugebauer, 1936, 259).

When we try to square this with Neugebauer's stated belief that we should be wary of generalizations about the distant past -the position quoted in the motto to this essay- the problems with such an argument only become more acute. Perhaps these 
evident difficulties help explain the intensely passionate language in the concluding parts of his text. The tone in The Exact Sciences in Antiquity is far milder, and yet his arguments remain substantively the same (Neugebauer, 1969, 146-151). There is even brief mention of the same quotation from Archytas, and one senses what Swerdlow might have meant when he wrote that Neugebauer grew bored with Greek mathematics (Swerdlow, 1993, 146).

Neugebauer's research represented part of a large-scale intrusion by mathematicians into a field that was formerly dominated by classicists. Before he entered the field the history of Greek mathematics was traditionally seen as strongly linked with the works and influence of Plato and Aristotle, a view that would later be contested by the influential American historian Wilbur Knorr (see, for example, the essays by Knorr in Christianidis 2004). Neugebauer's work thus struck a sympathetic chord among a younger generation of experts on Greek mathematics, even though he had left the field by the mid 1930s. Ever the anti-philosopher, he wanted to undermine the special German fascination with Greek philosophy, most particularly the Platonic tradition. In this respect, his work stood poles apart from that of Oskar Becker, or for that matter, Otto Toeplitz, both of whom, like Neugebauer, published regularly in Quellen und Studien. These two older contemporaries combined fine-tuned mathematical analyses with careful philological readings of classical Greek texts. Neugebauer, on the other hand, showed very little interest in studies of this kind. Furthermore, he had an entirely different agenda than they: he aimed to overthrow the standard historiography that made mathematics look like the handmaiden of Greek philosophy.

Neugebauer's original vision thus entailed a radical rewriting of the history of ancient mathematics and exact sciences. One of his central theses was that rigorous axiomatic reasoning in the style of Euclid arose rather late. At the same time he liked to call on the testimony of Archytas, a much earlier mathematician contemporaneous with Plato, who -according to Neugebauer's reading- tells us that the Greeks of that era understood the primacy of algebraic content over geometrical form. If one probed the later Greek sources with a mathematically trained eye -as Neugebauer tried to show in his study of Apollonius' Conica- what one found was a fundamentally algebraic style of thought. His revisionist stance also aimed to debunk the notion of a "Greek miracle" that sprang up during the sixth century from the shores of Ionia. Neugebauer was convinced that most of the sources that reported on the legendary feats of ancient heroes -Thales, Pythagoras, and their intellectual progeny- were just that: legends that had grown with the passing of time. So his constant watchword remained skepticism with regard to the accomplishments of the early Greeks, whereas Toeplitz, Becker, and others began to analyze extant sources with a critical eye toward their standards of exactness 5 .

5 See Christianidis 2004 for a recent account of older as well as the newer historiography on Greek mathematics. 


\section{Greek Mathematics Reconsidered}

One can well imagine that for some experts on ancient Greek philosophy and early science, Neugebauer's views regarding the historical development of Greek mathematics were simply anathema. On the other hand, he published almost nothing that dealt with early Greek mathematics per se, partly no doubt in order to avoid controversy. Still, he had a number of notable allies in classics who shared his general skepticism. In fact, a debate was then underway in which these skeptics questioned the level of truly scientific activity among the followers of $6^{\text {th }}$-century physiologoi, particularly the early Pythagoreans. German classical philology had witnessed a very different type of debate when Nietzsche published his Birth of Tragedy, but in a sense the parallel holds true. Leading classicists saw themselves as Kulturträger, which meant that they were quite accustomed to playing for "high stakes" (or at least imagining they were). Owing to their spiritual affinity with the ancient Greeks, they did not think of themselves as mere scholars: their discipline and special expertise carried with it an implicit social responsibility, namely to explain the deeper meaning of Greek ideals to that special class of German society, its Bildungsbürgertum, who perhaps alone could appreciate the true mission of the German people, especially when faced with momentous "worldhistorical" events like the Great War.

After Imperial Germany collapsed following that calamitous struggle, it should come as no surprise that fissures developed within the humanities and, in particular, the discipline of classical philology. This suggests that by the time Neugebauer brought forth his new vision for understanding the history of the exact sciences a quite general reorientation had long been underway among experts who specialized in classical Greek science and philosophy. At any rate, Neugebauer had plenty of good company. He could thus cite the work of classical scholars like Eva Sachs and Erich Frank -dubbed by their opponents as "hyper-critical" philologists- while defending his case for recasting the early history of Greek mathematics.

Thus, in a synopsis of (van der Waerden, 1940) for Mathematical Reviews, he wrote:

In the first paragraph the author shows that the famous paradoxa of Zeno (for example, of the tortoise and Achilles) are not at all directed against the infinite divisibility of geometrical magnitudes, but that their aim is simply to support the assumption of Parmenides that all movement is only a human fiction. The second part points out that in Zeno's time no mathematical theory of importance existed in which infinitesimal methods played a role. This fits in with the general concept of the development of Greek mathematics, which is familiar, at least since E. Frank's book "Plato und die sogenannten Pythagoreer" [Halle, 1923]. The last paragraph emphasizes that the so-called "crisis" of 
the foundation of Greek mathematics did not originate in the problem of infinite divisibility but from the discovery of irrationals (Neugebauer, 1940) ${ }^{6}$.

B. L. van der Waerden (1903-1996) was a distinguished Dutch mathematician who had taken a course on ancient mathematics with Neugebauer in Göttingen. They remained good friends and corresponded regularly about historical matters, but they also often disagreed. Only a year after he wrote the above, Neugebauer came back to the same issue while reporting on (van der Waerden 1941), a paper on Pythagorean astronomy: "The author gives an outline of the development of Greek astronomy in its earlier phases. He seems to have overlooked the book of E. Frank, Plato und die sogenannten Pythagoreer [Niemeyer, Halle, 1923], where essential points of his theory are already published" (Neugebauer, 1941).

Neugebauer's persistent references to Frank's book appear to have made no impression on van der Waerden, who remained in Leipzig after the Nazis rose to power. This makes it highly unlikely, of course, that he knew of Neugebauer's printed remarks from 1940-41, at least not until some time after the war had ended. Yet when he brought out the original Dutch edition of Science Awakening in 1950 -a more popular account of the exact sciences in antiquity that drew heavily on Neugebauer's researches- van der Waerden presented the legendary Pythagoras as the founder of a scientific school, one in which the sage's teachings had a profoundly mathematical character as opposed to the doctrines of a religious sect that practiced number mysticism.

Neugebauer, who was not Jewish, could have stayed on in Göttingen. After Courant's dismissal, he chose instead to leave for Copenhagen, where Harald Bohr arranged a three-year appointment beginning in January 1934. From this new outpost he continued editing Springer's Zentralblatt until 1938, at which point he resigned in protest of Nazi racial policies that had led to the removal of Jewish colleagues from its board. These events then paved the way for the founding of Mathematical Reviews, which Neugebauer co-managed beginning in 1940, after his arrival at Brown University. Courant, who was now teaching at New York University, had by this time severed his publishing connections with Springer. Ten days after the devastating blow to Jewish property and life during the Reichskristallnacht, he wrote to Ferdinand Springer informing him that he wished to resign as editor of the "yellow series" (Reid, 1976, 208-209). Still, Courant continued to maintain his former contacts in Göttingen after the war. He often visited the Mathematics Institute, whose new director Franz Rellich had earlier been part of the "Courant clique" that was forced to leave in 1933. Neugebauer, by contrast, refused ever to set foot in Germany again (he did visit Austria once or twice however).

6 Neugebauer here alludes to the so-called "foundations crisis" that supposedly ensued with the discovery of incommensurable magnitudes. This interpretation became popular during the 1920s, but later fell out of favour (Christianidis, 2004). 
Despite his loathing of the Nazis, Neugebauer steered clear of politics when commenting on the work of scholars whom he surely knew to be faithful followers of Hitler's brand of fanatical German nationalism. A striking example of this can be seen in his review of the German translation of the well-known Commentary on Book I of Euclid's Elements, written by the neo-Platonic philosopher Proclus in the fifth century. One should note that this rather large volume with extensive commentary by Max Steck, a hardcore Nazi from Munich, managed to get published in the year 1945. Neugebauer praised the work of the translator and then wrote this about Steck's contribution:

The introduction [33 pp.] contains many words which fortunately have no English equivalent, e.g., "deutscher Geistraum," "Geistschau," "in- und ausstrahlen," etc. By means of this "denkanschauend" method Proclus is made a founder of the German Idealismus for which Cusanus, Copernicus, Kepler, Hegel, Gauss (!) and many others are quoted. On the other hand, Proclus is considered as the culmination of Greek mathematics. The author here follows [Andreas] Speiser with whom he shares the tendency to consider the last phase of Greek metaphysics as representative of Greek mathematics. The subsequent commentary on Proclus shows the same contempt for the chronological element of history. There is hardly a combination of any pair of famous names missing, however great their distance may be (Neugebauer, 1945).

Once he was located in the United States Neugebauer published regularly in English in the Danish journal Centaurus as well as in numerous American publications, including George Sarton's Isis, the official journal of the History of Science Society. By the early 1950s, however, a first wave of negative reaction began to swell up among émigré scholars now residing in the United States. In 1951 Neugebauer's revisionist interpretation came under strong attack in Isis in an article entitled "Philolaos in Limbo, or: What Happened to the Pythagoreans?", written by Georgio de Santillana and Walter Pitts. The first author, well-known for his book The Crime of Galileo, had fled fascist Italy to take up a post at the Massachusetts Institute of Technology. Thus, it was fitting that the authors began their essay by citing these famous words: "Several years ago there was published in Rome a salutary edict which, in order to obviate the dangerous tendencies of our present age, imposed a seasonable silence upon the Pythagorean opinion that the earth moves..." They then proceeded to explain their present purpose:

These are the opening words of Galileo's preface to his Dialogue on the World Systems. One would be tempted to repeat them almost word for word today, apropos [sic] of certain contemporary philological research. The invisible edict or "trend" to which we refer has decreed that the whole development of Greek mathematics and astronomy must be condensed into a rather short interval of time around 400 B.C., so that almost all the mathematics, astronomy, and music theory of the "so-called Pythagoreans" becomes contemporary with Plato and his successors (Santillana and Pitts, 1951, 112). 
Three different groups are then identified as being responsible for this trend. The first of these is only vaguely named by alluding to "the massed power of Platonic and Aristotelian scholarship." Far more important for their critique is the role played by the aforementioned "hyper-critical philologists", especially Sachs and Frank, but also the American, W. A. Heidel, author of "The Pythagoreans and Greek Mathematics" (Heidel, 1940). Erich Frank, who had succeeded Heidegger in 1928 as professor of philosophy in Marburg, had been forced to flee Germany after losing this chair in 1935; he eventually came to Harvard as a Rockefeller Fellow. Unable to secure regular employment in the United States, he died in Amsterdam in 1949. His older study (Frank, 1923) argued that when Aristotle spoke about "so-called Pythagoreans" he was referring to the circle around Archytas of Tarentum, who was a friend of Plato as well as a gifted mathematician. This argument supported Frank's larger thesis, according to which the early Pythagoreans were merely a religious sect and played no substantive role in early Greek science.

The third group of trend setters was "the recent school of scientific historians which has attempted to trace the connection between Babylonian and Greek mathematics." Several works are cited by three authors: Neugebauer, van der Waerden, and the mathematician Kurt Reidemeister. "Relying on Frank," it is charged, "these authors have dismissed the entire tradition about early Greek mathematics, and supplanted it either with a most improbably late transference of Babylonian mathematics to Greece in the Vth century, or else have tried to fill the gap with speculations, conceived certainly in a true and subtle mathematician's spirit, derived from conjectural traces in Euclid and Plato" (ibid.). Having identified Erich Frank as the key culprit responsible for this hyper-critical treatment of sources on the Pre-Socratics -in the present case the authenticity of fragments attributed to the Pythagorean Philolaos form the principal matter under dispute- de Santillana and Pitts proceed to demolish the arguments in his book. Since Frank was no longer among the living, there was small chance for a rebuttal, although they also chided the distinguished classicist Harold Cherniss for having been duped by Frank's arguments regarding the authenticity of the Philolaos fragments (Cherniss, 1935, 386).

The year 1951 also saw the publication of the original Copenhagen edition of The Exact Sciences in Antiquity. It was reviewed at length in Isis by George Sarton and Francis Carmody, who noted that no one but Neugebauer could have written such a book. Sarton also paid tribute to Cornell University for its role in helping the author produce this idiosyncratic synthesis based on his six Messenger Lectures from 1949. This opportunity, Sarton felt sure, gave Neugebauer just the incentive he needed to address a broader set of historical issues, something he was otherwise loathe to do. In his review, Sarton put the matter this way: "as he does not like synthetic work and even affects to despise it, he would probably not have written this book without that flattering invitation, and we, his readers, would have been the losers" (Sarton, 1952, 69).

One can easily read between the lines here, since Sarton, the doyen of American historians of science, certainly saw himself as a leading representative of that very 
genre of scholarship to which he here alluded. Nor was this review altogether positive. The reviewers voiced skepticism, for example, when it came to Neugebauer's claims regarding the historical impact of Babylonian mathematics and astronomy. Noting that neither Hipparchus nor Ptolemy made mention of earlier Babylonian theoretical contributions, they wondered how historians could ever know that these Greek astronomers drew on such sources? As for Babylonian algebra, why should we assume that this knowledge survived long after the period of Hammurabi when there is no extant evidence for a continuous tradition of high mathematical culture in Mesopotamia? And if such mathematical knowledge persisted, how was it transmitted? After all, the complexity of the Babylonian algebraic and astronomical techniques required an expertise similar to Neugebauer's own. Sarton also took sharp issue with Neugebauer over the centrality of Hellenistic science, especially his claim that this melting pot of ancient science later spread to India before entering Western Europe, where it held sway until the time of Newton. In Sarton's view, the Hellenistic period marked the final phase of Babylonian science, though they admitted some slight influences on both the Indian and Islamic cultural spheres. For the most part, however, he contrasted the larger longterm impact of Greek science with the relatively meager legacy of the Babylonian tradition. For him, this was the gravest shortcoming of all; how could Neugebauer write a book called The Exact Sciences in Antiquity and virtually ignore the achievements of the Greeks? Doing that was comparable to writing a play entitled Hamlet while leaving out the figure of Hamlet himself. With that quip he could chide Neugebauer's Danish editors -identified as Zeuthen's countrymen- for allowing their distinguished friend to make such a blunder.

Sarton's criticisms reflect the views of a generalist who clearly found Neugebauer's overall framework far from convincing. He had the highest respect for the author's specialized contributions to research on the ancient exact sciences -work that required not only formidable mathematical abilities but also immense discipline- but this review makes plain that he saw Neugebauer's book as the product of a remarkable specialist. Sarton's overall verdict -seen from his personal vantage point as someone who hoped to open inroads for the history of science within the curriculum of American higher education- echoed Neugebauer's own forthright opinion that he "did not like synthetic work". Exact Sciences, Sarton opined, was of limited value for introductory courses; it should not and could not be taken as a model for teaching the history of ancient science. Though full of nicely chosen anecdotes and a good deal of general information, it simply did not pass muster as a global account of the history of the exact sciences in ancient cultures. Noel Swerdlow later expressed a very different opinion when he wrote: "Neugebauer here allowed himself the freedom to comment on subjects from antiquity to the Renaissance. The expert can learn something from it, and from its notes, every time it is read, and for the general reader it is, in my opinion, the finest book ever written on any aspect of ancient science" (Swerdlow, 1993, 156).

George Sarton saw himself as a champion of what he called a synthetic approach to the history of mathematics (Sarton, 1936b, 11). What Neugebauer thought about 
this can well be surmised from the preface to the first edition of Exact Sciences in Antiquity: "I am exceedingly skeptical of any attempt to reach a "synthesis" -whatever this term may mean - and I am convinced that specialization is the only basis of sound knowledge" (Neugebauer, 1969, vii-viii). Paging through Sarton's booklet, The Study of the History of Mathematics, one can easily understand Neugebauer's dismissive attitude. There one reads that:

The main reason for studying the history of mathematics, or the history of any science, is purely humanistic. Being men, we are interested in other men, and especially in such men as have helped us to fulfill our highest destiny. As soon as we realize the great part played by individual men in mathematical discoveries - for, however these may be determined, they cannot be brought about except by means of human brains-, we are anxious to know all their circumstances (Sarton, 1936b, 12).

Sarton's humanistic approach to the history of mathematics thus derives from simple human curiosity, which he admits is the same instinct that feeds public fascination with murderers. Whereas newspapers skillfully exploit this "insatiable desire to know every detail of a murder case, those who are more thoughtful wish to investigate every detail of scientific discoveries or other creative achievements" (ibid.). This loftier interest apparently has much to do with Sarton's sympathy for hero worship: "One soon realizes that mathematicians are much like other men, except in the single respect of their special genius, and that genius itself has many shapes and aspects" (ibid.).

Not surprisingly, Neugebauer drew a sharp line between his work and that of dabblers like Sarton, though he never launched a frontal attack on the latter's own works. He did, however, occasionally publish critical responses to Sarton's opinions in Isis, one of which sheds much light on the intellectual fault lines that divided them. In a review of B. L. van der Waerden's Science Awakening, Sarton expressed dismay over the author's "shocking ingratitude" towards Moritz Cantor, whom he called "one of the greatest scholars of [the] last century, a man to whom every historian of mathematics owes deep gratitude." After citing this passage, Neugebauer went on to explain why he was writing this "Notice of Ingratitude" (Neugebauer, 1956):

Since I must conclude that this statement in its generality would also apply to myself, I should like to point out that I never felt a trace of indebtedness to Cantor's voluminous production. I do not deny, of course, the fact that it had a great influence, though in a direction quite opposite to what Professor Sarton's statement implies. I always felt that its total lack of mathematical competence as well as its moralizing and anecdotal attitude seriously discredited the history of mathematics in the eyes of mathematicians, for whom, after all, the history of mathematics has to be written. In methodological respects, Cantor's work might be of some value for historians of science since it contains so many drastic examples of how one should not approach a problem... If Cantor had not philosophized about a goose counting her young or about oriental mathematics, which was equally inaccessible to him, but instead had studied the texts themselves, he would have 
avoided countless misinterpretations and inaccuracies which have become commonplace. It was with good reasons that the Bibliotheca Mathematica for years ran a special column devoted to corrections of errors in Cantor's Geschichte der Mathematik. But no amount of corrections can ever remedy consistent mediocrity (Neugebauer, 1956, 58).

Given that Neugebauer's academic career was decisively shaped by his training and background as a mathematician, one can easily understand his aversion to the writings of Cantor and Sarton. He was most definitely not a "synthetic" historian in the sense of Sarton, but we can say just as assuredly that his work was guided by a larger view of the history of mathematics. His was an approach to history deeply grounded in the mathematical culture he grew up in, and his sensibilities as a historian were from the very beginning guided by a grandiose vision. Neugebauer worked on details, but always with a larger landscape in mind. His attitude toward his own work seems to have also contained elements of playful irony. When he came to the end of his Messenger lectures on the exact sciences in antiquity, he offered a simile to describe the historian's craft:

In the Cloisters of the Metropolitan Museum in New York there hangs a magnificent tapestry which tells the tale of the Unicorn [Fig. 3]. At the end we see the miraculous animal captured, gracefully resigned to his fate, standing in an enclosure surrounded by a neat little fence. This picture may serve as a simile for what we have attempted here. We have artfully erected from small bits of evidence the fence inside which we hope to have enclosed what may appear as a possible, living creature. Reality, however, may be vastly different from the product of our imagination; perhaps it is vain to hope for anything more than a picture which is pleasing to the constructive mind when we try to restore the past (Neugebauer, 1969, 177).

David E. Rowe

Institut für Mathematik

Johannes Gutenberg Universität Mainz

Staudingerweg 9

D-55128 Mainz

rowe@mathematik.uni-mainz.de

\section{Bibliography}

Cherniss, Harold. 1935. Aristotle's Criticism of the Presocratics, Baltimore: Johns Hopkins Press.

Christianidis, Jean, ed. 2004. Classics in the History of Greek Mathematics, Dordrecht: Kluwer.

Fowler, David H. 1999. The Mathematics of Plato's Academy. A New Reconstruction, $2^{\text {nd }}$ ed., Oxford: Oxford University Press. 
Frank, Erich. 1923. Plato und die sogenannten Pythagoreer: ein Kapitel aus der Geschichte des griechischen Geistes, Halle: Niemeyer.

Heath, Thomas L., ed. 1956. The Thirteen Books of Euclid's Elements, vol. 1, New York: Dover.

Heidel, W.A. 1940. "The Pythagoreans and Greek Mathematics”, American Journal of Philosophy: 1-33.

Klein, Jakob. 1936. "Die griechische Logistik und die Entstehung der Algebra", Quellen und Studien zur Geschichte der Mathematik, Astronomie und Physik, B: Studien, 3: 18-105; 122-235.

Klein, Jakob. 1968. Greek Mathematical Thought and the Origin of Algebra, trans. Eva Brann, Cambridge, MA: MIT Press.

Neugebauer, Otto. 1925. "Litteraturanmeldelse" (T. E. Peet, The Rhind Mathematical Papyrus), Matematisk Tidsskrift A, 66-70.

Neugebauer, Otto. 1927. "Zur Entstehung des Sexagesimalsystems", Abhandlungen der Akadamie der Wissenshaften zu Göttingen, 13: 1-55.

Neugebauer, Otto. 1932. "Apollonius-Studien”, Quellen und Studien zur Geschichte der Mathematik, Astronomie und Physik, B: Studien, 2: 215-254.

Neugebauer, Otto. 1934. Vorlesungen über Geschichte der antiken mathematischen Wissenschaften, Erster Band: Vorgriechische Mathematik, Berlin: Verlag Julius Springer.

Neugebauer, Otto. 1936. "Zur geometrischen Algebra (Studien zur Geschichte der Algebra III)", Quellen und Studien zur Geschichte der Mathematik, Astronomie und Physik, B: Studien, 3: 245-259.

Neugebauer, Otto. 1940. "Review of (van der Waerden 1940)", Mathematical Reviews.

Neugebauer, Otto. 1941. "Review of (van der Waerden 1941)", Mathematical Reviews.

Neugebauer, Otto. 1945. "Review of (Steck 1945)", Mathematical Reviews.

Neugebauer, Otto. 1956. "A Notice of Ingratitude”, Isis, 47: 58.

Neugebauer, Otto. 1963. "Reminiscences on the Göttingen Mathematical Institute on the Occasion of R. Courant's 75th Birthday”, Otto Neugebauer Papers, Box 14, publications vol. 11.

Neugebauer, Otto. 1969. The Exact Sciences in Antiquity, $2^{\text {nd }}$ rev. ed., New York: Dover.

Pyenson, Lewis. 1995. "Inventory as a Route to Understanding: Sarton, Neugebauer, and Sources", History of Science, 33(3): 253-282.

Reid, Constance. 1976. Courant in Göttingen and New York: the Story of an Improbable Mathematician, New York: Springer Verlag.

Remmert, Volker and Schneider, Ute. 2010. Eine Disziplin und ibre Verleger. Disziplinenkultur und Publikationswesen der Mathematik in Deutschland, 18711949, Bielefeld: Transkript. 
Rowe, David E. 1986. “Jewish Mathematics“ at Göttingen in the Era of Felix Klein”, Isis 77: 422-449.

Rowe, David E. 2004. "Making Mathematics in an Oral Culture: Göttingen in the Era of Klein and Hilber", Science in Context, 17(1/2): 85-129.

Rowe, David E. 2012. "Otto Neugebauer and Richard Courant: On Exporting the Göttingen Approach to the History of Mathematics", The Mathematical Intelligencer, 34(2): 29-37.

de Santillana, George and Pitts, Walter. 1951. "Philolaos in Limbo, or: What Happened to the Pythagoreans?", Isis, 42(2): 112-120.

Sarton, George. 1936a. The Study of the History of Science, with an Introductory Bibliography, Cambridge: Harvard University Press.

Sarton, George. 1936b. The Study of the History of Mathematics, Cambridge: Harvard University Press.

Sarton, George. 1952. "Review of Otto Neugebauer, The Exact Sciences in Antiquity", Isis, 43(1): 69-73.

Siegmund-Schultze, Reinhard. 2009. Mathematicians Fleeing from Nazi Germany: Individual Fates and Global Impact, Princeton: Princeton University Press.

Steck, Max, Hrsg. 1945. Proklus Diadochus, Kommentar zum ersten Buch von Euklids "Elementen", übers, Halle.

Swerdlow, Noel M. 1993. "Otto E. Neugebauer (26 May 1899-19 February 1990)”, Proceedings of the American Philosophical Society, 137(1): 138-165.

Unguru, Sabetai. 1975. "On the Need to Rewrite the History of Greek Mathematics", Archive for History of Exact Sciences, 15: 67-114.

van der Waerden, B. L. 1940. "Zenon und die Grundlagenkrise der griechischen Mathematik", Mathematische Annalen, 117: 141-161.

van der Waerden, B. L. 1941. "Die Astronomie der Pythagoreer und die Entstehung des geozentrischen Weltbilde", Himmelswelt 51: 97-103, 113-119.

Zeuthen, H. G. 1896. Geschichte der Mathematik im Altertum und Mittelalter, Kopenhagen: Verlag A. F. Hoest. 


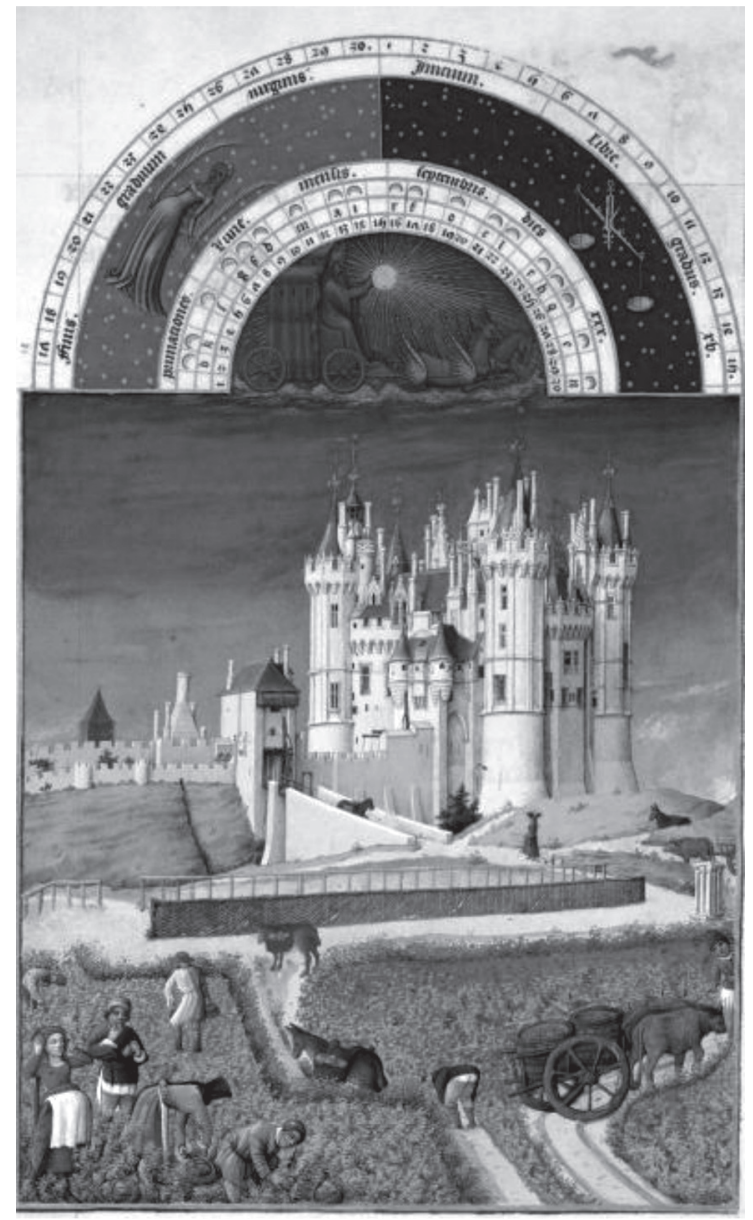

Fig. 1: Septembre from the Très Riches Heures du Duc de Berry, one of the most famous works in the French Gothic tradition. The manuscript first gained public attention after 1856 when it was acquired by the Duc d'Aumale, founder of the Musée Condé in Chantilly.

From O. Neugebauer, The Exact Sciences in Antiquity, Princeton-Oxford 1951. 


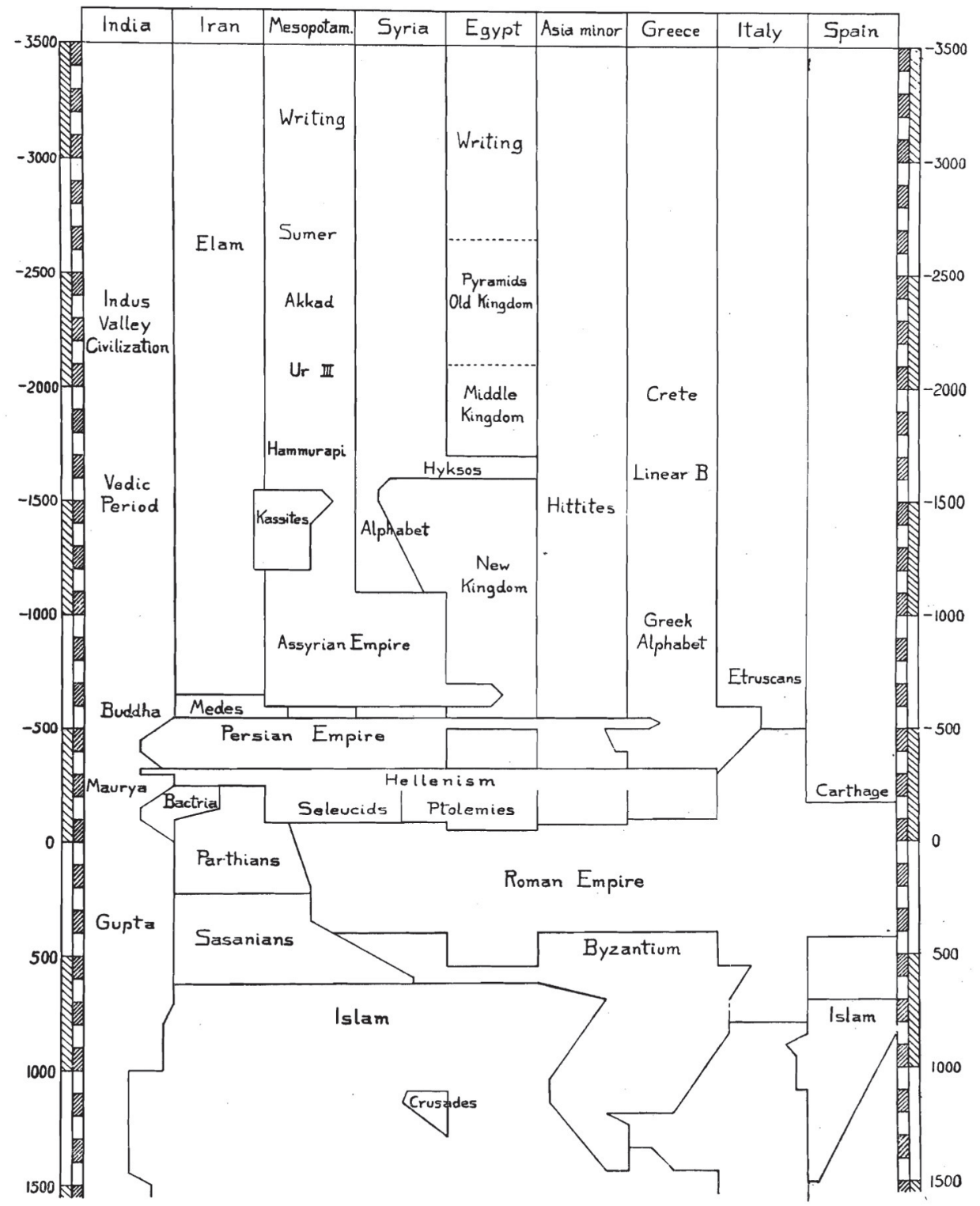

Fig. 2: Neugebauer began The Exact Sciences in Antiquity with this chronological scheme in which the melting pot of Hellenism occupies a central place. The origins and transmission of this Hellenistic science thus form the two central problems that motivated his historical investigations. 


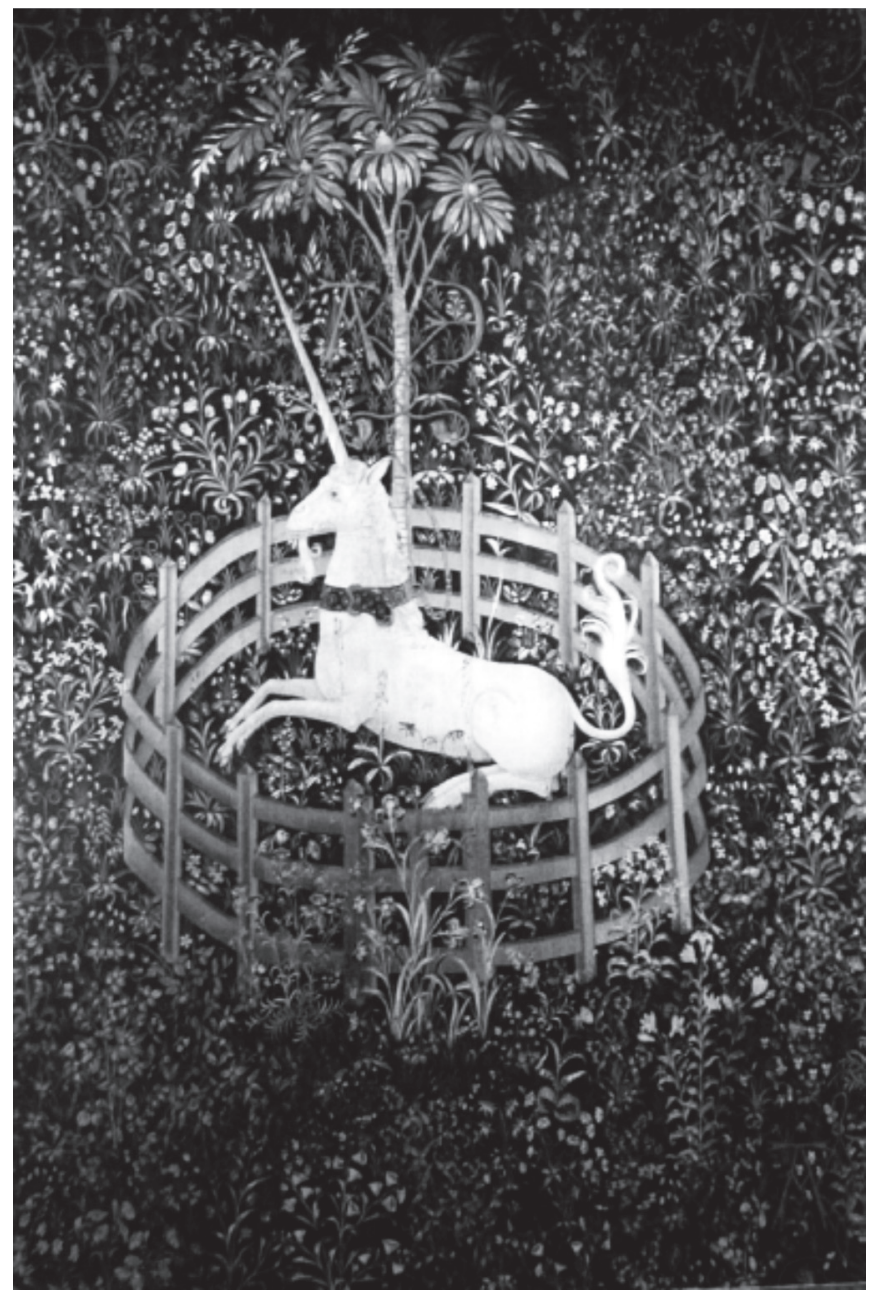

Fig. 3: The Unicorn in Captivity, one of seven tapestries dating from ca. 1500 located in The Cloisters in New York. In the pagan tradition, the unicorn was a one-horned creature that could only be tamed by a virgin; whereas Christians made this into an allegory for Christ's relationship with the Virgin Mary. 